\title{
HISTÓRIA DIGITAL: REFLEXÕES A PARTIR DA HEMEROTECA DIGITAL BRASILEIRA E DO USO DE CAQDAS NA REELABORAÇÃO DA PESQUISA HISTÓRICA
}

Digital History: reflections from the Brazilian Digital Hemerotheque and the use of CAQDAS in the re-elaboration of historical research

Historia digital: reflexiones de la Hemeroteca Digital Brasileña y el uso de CAQDAS en la reelaboración de la investigación histórica

ERIC BRASIL ${ }^{\text {I* }}$

LEONARDO FERNANDES NASCIMENTO ${ }^{\mathrm{I}{ }^{* * *}}$

DOI: http://dx.doi.org/10.1590/\$2178-14942020000100011

\footnotetext{
' Universidade da Integração Internacional da Lusofonia Afro-brasileira (Unilab/Malês) Bahia (BA), Brarsil.

* Professor de História da América da Universidade da Integração Internacional da Lusofonia Afro-brasileira, Campus dos Malês (UNILAB/Malês) (profericbrasil@gmail.com). ORCID ID: http://orcid.org/0000-0001-5067-8475.

" Universidade Federal da Bahia (ICTI/UFBA), Bahia (BA), Brasil.

** Professor do Instituto de Ciências, Tecnologia e Inovação da Universidade Federal da Bahia (ICTI/UFBA), Brasil. Coordenador do Laboratório de Humanidades Digitais da UFBA (LABHD/UFBA) (leofn@ufba.com). ORCID ID: http://orcid.org/0000-0003-2929-1115.

Artigo recebido em $1^{\circ}$ de agosto de 2019 e aprovado para publicação em 3 de dezembro de 2019 .
} 


\title{
RESUMO
}

0 presente artigo pretende discutir o papel do uso de ferramentas digitais na pesquisa e na escrita da história, refletindo sobre as transformações e os desafios no modo de produção do conhecimento na prática de investigação da ciência histórica, abordando dois aspectos fundamentais: a) o progressivo uso de fontes de pesquisa provenientes de acervos ou repositórios digitais, por meio da análise da Hemeroteca Digital Brasileira (HDB) da Biblioteca Nacional (BN); e b) a maneira como os aplicativos de análises de dados qualitativos - CAQDAS, acrônimo do inglês computer assisted qualitative data analysis software - podem servir para minimizar os problemas e as limitações gerados pelo uso inadvertido e com pouco rigor metodológico das ferramentas digitais. Aqui, utilizaremos o programa ATLAS.ti como exemplo. Concluímos que a busca e a análise digital transformam não apenas a pesquisa histórica, mas possibilitam novas perguntas, problemas e respostas, impactando tanto a teoria quanto o método da disciplina.

PALAVRAS-CHAVE: História digital; Hemeroteca Digital Brasileira; ATLAS.ti.

\begin{abstract}
This paper aims to discuss the role of the use of digital tools in the research and writing of history, reflecting on the transformations and challenges in the mode of knowledge production in the practice of historical science research, addressing two fundamental aspects: a) the progressive use of research sources from digital collections or repositories, through the analysis of the Brazilian Digital Newspaper Library (HDB); and b) The way qualitative data analysis applications (CAQDAS) can serve to minimize the problems and limitations that are generated by inadvertently using and little methodological rigor in digital tools. Here we will use the program ATLAS.ti as an example. We conclude that digital search and analysis not only transforms historical research, but enables new questions, problems and answers, impacting both the theory and the method of the discipline.
\end{abstract}

KEYWORDS: Digital history; Brazilian Digital Newspaper Library; ATLAS.ti.

\section{RESUMEN}

Este documento tiene como objetivo discutir el papel del uso de herramientas digitales en la investigación y escritura de la historia, reflexionando sobre las transformaciones y desafíos en el modo de producción de conocimiento en la práctica de la investigación científica histórica, abordando dos aspectos fundamentales: a) el uso progresivo de fuentes de investigación de colecciones o repositorios digitales, a través del análisis de la Hemeroteca Digital Brasileña (HDB) de la Biblioteca Nacional (BN); y b) la forma en que las aplicaciones de análisis de datos cualitativos (CAQDAS) pueden servir para minimizar los problemas y limitaciones generados por el uso inadvertido y metodológicamente inexacto de las herramientas digitales. Aquí usaremos el programa ATLAS.ti como ejemplo. Concluimos que la búsqueda y el análisis digital no solo transforman la investigación histórica, sino que permiten nuevas preguntas, problemas y respuestas, impactando tanto en la teoría como en el método de la disciplina.

PALABRAS CLAVE: Historia digital; Hemeroteca Digital Brasileña; ATLAS.ti. 


\section{INTRODUÇÃO}

0 presente artigo pretende discutir o papel — cada vez mais preponderante — do uso de ferramentas digitais na pesquisa e na escrita da história. Mais especificamente, a ideia é investigar as transformações e os desafios no modo de produção do conhecimento na prática de investigação da ciência histórica, abordando dois aspectos fundamentais: a) o progressivo uso de fontes de pesquisa provenientes de acervos ou repositórios digitais (a partir do caso da Hemeroteca Digital Brasileira [HDB] da Biblioteca Nacional [BN]); e b) a maneira como os aplicativos de análises de dados qualitativos podem servir para minimizar os problemas e as limitações gerados pelo uso inadvertido e com pouco rigor metodológico dos dados desses repositórios.

A seção seguinte descreve alguns aspectos relacionados com a questão da digitalização da vida e das práticas de pesquisa, proporcionando, especificamente, alterações na maneira da ciência histórica e no aparecimento do campo da história digital. Em seguida, detalharemos as fontes digitais de pesquisa e as modificações que elas apresentam. Na penúltima parte, vamos considerar, de maneira mais aprofundada, uma pesquisa historiográfica que foi realizada utilizando a HDB-BN. Por fim, encerramos, apresentando, ainda que de maneira breve, 0 aplicativo ATLAS.ti para o tratamento de fontes históricas no formato digital.

\section{HISTÓRIA DIGITAL COMO PROBLEMA}

Q uando o primeiro autor deste artigo viu a chamada para o dossiê sobre humanidades digitais, ele compartilhou o hiperlink e convidou o segundo autor por meio de um aplicativo de mensagens. Em seguida, o mesmo aplicativo serviu para estabelecerem uma reunião de organização da proposta. Ao longo de alguns meses, eles compartilharam, por um serviço pago, uma pasta de trabalho com os mesmos arquivos entre seus computadores pessoais e que atualizava em ambos qualquer alteração. Duas dezenas ou mais de e-mails foram enviados entre eles, e foram realizadas incontáveis buscas na World Wide Web. Por fim, a própria forma como escreveram o artigo deu-se por meio de um editor de texto em um computador ou, como se tornou lugar-comum dizermos, em um "meio digital".

O leitor provavelmente já deve conhecer todos ou a maioria dos serviços e aplicativos a que nos referimos. No entanto, para podermos apresentar o problema que vamos tratar neste artigo, decidimos começar "desnaturalizando" alguns dos chamados fenômenos digitais. É comum que a grandeza ou a magnitude de uma mudança seja diretamente proporcional à dificuldade de pensarmos o mundo que antecedeu essa mesma mudança. Em outras palavras, 
as gerações contemporâneas que cresceram sob a égide das tecnologias digitais de informação e comunicação (TDICs) são cada vez menos capazes de imaginar como era o mundo que antecedeu 0 advento dos computadores e da internet.

Isso ocorre porque as novas formas de localização no espaço, de buscar informações, de nos relacionarmos, de ler livros, de ouvir música, de viajar, de fazer compras etc. proporcionam um mundo bastante diferente do que havíamos construído anteriormente. Concordamos com Fish (2011: 8), quando retoma Marcel Mauss e considera o digital como um "fato [ou fenômeno] social total", querendo sugerir que nenhum aspecto da vida contemporânea permaneceu incólume diante das transformações ocasionadas pelas TDICs. ${ }^{1}$ A prática da pesquisa científica, por seu turno, nunca se furtou a tais mudanças. Ao contrário, desde seus primórdios - pensemos, por exemplo, em Galileu e sua luneta - a ciência sempre esteve na dianteira da utilização de diferentes tecnologias. Se isso é bem evidente nos campos científicos mais experimentais, o que podemos dizer sobre as humanidades? Atualmente, já temos algumas reflexões importantes na área de sociologia, geografia e ciência política sobre a utilização de recursos digitais, digitalização de fontes, utilização de softwares de análise qualitativa de grandes bases de dados, georreferenciamento e seus impactos nos resultados da pesquisa. Os debates sobre as TDICs e os diferentes campos das ciências humanas propiciaram o surgimento de campos híbridos como o das humanidades digitais (Berry, 2012; Gold, 2012; Schreibman, Siemens e Unsworth, 2008), que vêm ganhando terreno em diferentes espaços acadêmicos. Trata-se, antes de tudo, de um campo transdisciplinar em desenvolvimento, pois agrega métodos, dispositivos e perspectivas analíticas das ciências humanas e sociais, ao mesmo tempo que mobiliza as ferramentas e abordagens singulares abertas pela tecnologia digital.

Tais discussões ainda estão bastante incipientes no campo da história. No Brasil, há algumas iniciativas e reflexões importantes que indicam a possibilidade de crescimento e fortalecimento de um campo de estudos sobre a história digital sendo produzidos nos últimos cinco anos: trabalhos sobre história oral, história pública, memória e patrimônio, história do tempo presente, assim como pesquisas sobre videogames, cinema, georreferenciamento e ensino de história. ${ }^{2}$ Entretanto, a produção ainda é muito pequena, e os esforços de reflexão teórica e metodológica são ainda menores. Muitas pesquisas atuais na área de história têm utilizado recursos digitais sem que o pesquisador empenhe-se em realizar um debate aprofundado sobre as especificidades teórico-metodológicas de sua utilização. Segundo Hitchcock (2013: 12), os historiadores têm menosprezado o impacto das novas tecnologias. Para ele, a história como disciplina "em grande parte não está envolvida na produção de recursos digitais e, aparentemente, não está interessada em mudar a forma como o seu conhecimento se 
acomoda ao digital, colocou sua cabeça na areia e tentou ignorar toda a questão". Em artigo mais recente e bastante crítico sobre como historiadores vêm encarando a "virada digital", Laura Putnam (2016: 388) afirma que as práticas digitais de pesquisa comumente utilizadas (buscas no Google, utilização de repositórios de fontes digitalizadas, e-mails, aplicativos de edição de textos, planilhas etc.)

[...] caem no reino do método invisível, a caixa-preta onde, por consenso, deixamos muito do trabalho pesado de nossa disciplina. A extensa discussão da digitalização em andamento nos periódicos de ciência da informação está em nítido contraste com o silêncio sobre esse tema nas principais publicações de historiadores.

Embora atualmente tal panorama esteja sendo progressivamente alterado - e o presente dossiê constitui um esforço nesse sentido — - ainda permanece uma urgente tarefa levantarmos as seguintes questões: Existem diferenças substanciais entre as fontes digitais e/ ou digitalizadas e as fontes "tradicionais", em papel? 0 uso de ferramentas digitais na prática de pesquisa é capaz de modificar os processos, a percepção, a intuição e a interpretação da história? Por fim, estariam as tecnologias digitais proporcionando algum tipo de mudança na prática de pesquisa do historiador e de sua imaginação e escrita historiográfica? Se, ainda que parcialmente, respondemos positivamente a essas questões, resta-nos delinear as características dessas transformações e suas limitações.

\section{AS FONTES DIGITAIS DE PESQUISA}

ara além da produção dos documentos primários digitais exclusivos que todos nós estamos produzindo neste exato momento, por meio de e-mails, redes sociais, plataformas de busca etc., a história precisa refletir também sobre a digitalização das fontes e os impactos das ferramentas digitais no trabalho do historiador. Nesse sentido, William Thomas III (Cohen et al., 2008: 454) define história digital da seguinte maneira:

A história digital é uma abordagem para examinar e representar o passado que funciona em conjunto com as novas tecnologias de comunicação computadorizadas, a rede da Internet e os sistemas de software. Em um nível, a história digital é uma arena aberta de produção e comunicação acadêmica, abrangendo o desenvolvimento de novos materiais didáticos e coleções de dados acadêmicos. Por outro lado, trata-se de uma abordagem metodológica enquadrada pelo poder hipertextual dessas tecnologias em fazer, definir, consultar e anotar associações no registro humano do passado. Fazer história digital, então, é criar uma estrutura, uma ontologia, através da tecnologia para as pessoas experimentarem, lerem e seguirem uma discussão sobre um problema histórico. 
Quando um registro histórico — seja ele um manuscrito, uma carta, uma edição de jornal, uma foto, um livro etc. — converte-se, por meio de algum processo computacional, em um documento digital, ocorre aí uma mudança que dificilmente poderia ser considerada trivial. Apesar de a informação contida na fonte continuar "sendo a mesma" — no sentido de que a digitalização não alteraria substancialmente o conteúdo do registro histórico —, podemos dizer que a modificação na "materialidade" da fonte histórica nos conduz, inevitavelmente, a uma nova condição em relação ao modo de lidarmos com a informação ali contida. Se concordarmos que, no "setor da informática, não há nada de virtual" (Vinck, 2016: 37) — pois os arquivos digitais "ocupam espaço" em servidores, cabos, antenas, hard disk drives etc. - , a desmaterialização não é senão uma rematerialização (Vinck, 2016: 36).

É possível, desse modo, considerarmos essa rematerialização em um duplo aspecto. 0 primeiro deles, ainda que seja um pleonasmo, é que a cópia digitalizada — diferentemente dos documentos nativamente digitais, isto é, aqueles já surgem em formato digital — é uma cópia de um objeto real. E toda cópia, para que seja considerada "verdadeira" — no sentido de semelhante ou fidedigna ao original — , exige uma forma relativamente fixa, em termos de um conteúdo estável, uma procedência e um contexto que assegurem que a digitalização foi bem-sucedida: a inteireza do conteúdo necessita de fato estar presente na cópia digitalizada, aquilo que os arquivistas denominam cadeia de custódia. Em outros termos, qualquer tipo de erro, negligência ou até mesmo má-fé no processo computacional pertinente à digitalização será determinante no trabalho historiográfico. Além disso, a rematerialização envolve o desaparecimento parcial ou total de uma considerável gama de propriedades organolépticas (a cor, o brilho, a luz, o odor, a textura, a maciez, o som, o sabor etc.) que, de fato, podem ser determinantes na descrição de determinadas fontes históricas.

Por fim, a cópia digital, decaída ou elevada à condição da "nova materialidade digital dos bits", adquire o conhecido caráter de reprodutibilidade. Em outras palavras, assim como ocorre com todo "arquivo" de computador, é possível fazer cópias do registro histórico digital — em certa medida e asseguradas algumas condições — indefinidamente. Com isso, a possibilidade de acesso ao registro histórico amplifica-se, ou, para usarmos um termo muito em voga, ele "viraliza". Isso nos conduz ao segundo aspecto da mudança de materialidade: ao ser digitalizada, a fonte torna-se dataficável. Um documento de texto, por exemplo, converte-se em uma base de dados de strings, termo que, na programação de computadores, representa uma cadeia ou sequência de caracteres: as fotos ganham regiões medidas em pixels; os registros, em áudio, diferentes comprimentos de onda. 
Além do "dado" referente ao conteúdo da fonte, a digitalização instaura a presença de metadados, isto é, "dados sobre os dados". Os metadados são constituídos por aquelas informações complementares sobre o conteúdo da informação (qual tipo de informação os objetos contêm), o contexto da informação (indica quem, o quê, por que, onde e como estão associados à informação) e a estrutura da informação (a relação entre os diferentes tipos de informações) (Baca, 2008). São os metadados que explicam, contextualizam, conferem veracidade ao documento. No caso especifico de documentos de texto, ocorre algo ainda mais peculiar e que constitui o cerne do processo de dataficação: os dados e metadados podem vir a se tornar pesquisáveis. Qualquer documento textual que passe por um scanner e pelo tratamento por softwares de reconhecimento óptico dos caracteres 3 permite ao historiador a busca de ocorrências de palavras-chave ao longo de toda a sua extensão.

A dataficação (Mayer-Schönberger e Cukier, 2013), possibilitada pela digitalização das fontes históricas, não é, de modo algum, um fenômeno novo (Ayers, 2001; Bolick, 2006). De maneira similar, os livros digitais e o hipertexto já haviam instaurado uma nova relação entre 0 leitor e o texto, segundo aquilo que foi descrito pelo historiador Roger Chartier (2002: 23-24) como uma tríplice ruptura: "assim, quanto à ordem dos discursos, o mundo eletrônico provoca uma tríplice ruptura: propõe uma nova técnica de difusão da escrita, incita uma nova relação com os textos, impõe-lhes uma nova forma de inscrição)." .

Primeiramente, vejamos a questão da difusão das fontes históricas. A possibilidade de cópia digital dos arquivos, o surgimento de gigantescos repositórios, em diversos idiomas e com diferentes tipos de acervo, descortinariam um mundo de pesquisas e achados que até então era difícil imaginar.

Esses projetos [de arquivos digitalizados], exibindo coleções de dados numéricos, textos, imagens, mapas e sons, criam grandes repositórios[,] proporcionando espaços nos quais os usuários fazem conexões e descobertas por si mesmos. Tais arquivos aproveitam a massa, a multiplicidade, a velocidade, a reiteração, a reflexividade e a precisão oferecidas pelos computadores. (Ayers, 2001: 6)

Entretanto, a possibilidade da criação de cópias idênticas pode gerar um impacto profundo na primeira tarefa básica do método histórico mais elementar: a heurística. $A$ análise crítica do conteúdo da fonte é fundamental no fazer historiográfico. Segundo Bresciano, a crítica heurística pressupõe fazer a história da própria fonte, de sua criação até o momento da análise, passando pela reflexão sobre as características do suporte, sua estrutura formal, o perfil do discurso e do léxico utilizado, e a "coerência entre os dados que apresenta e as informações contextuais disponíveis" (Gil e Bresciano, 2015: 37). 
Por outro lado, Bresciano também chama a atenção para a necessidade de uma heurística digital e usa o trabalho de Chaudhuri para caracterizá-la. É preciso investigar os metadados, verificar a existência de marcas d'água; revisar na internet a existência de modelos que poderiam ter sido usados para fraudar os documentos; comprovar se os conteúdos podem ser sustentados ou verificados por outras fontes; confirmar os conteúdos gerais em buscas online; avaliar a congruência de dados específicos, como datas e lugares; detectar erros de transcrição de nomes próprios e de instituições públicas e privadas (Chaudhuri, 2007 apud Gil e Bresciano, 2015: 38). 0 trabalho do historiador diante do arquivo digital, portanto, não é tão diferente do trabalho diante do arquivo físico, pois exige tanto rigor metodológico no tratamento da fonte quanto o tratamento de uma fonte não digital. Entretanto, esse cuidado muitas vezes é escamoteado ante a profusão de fontes, a agilidade da busca, a velocidade do acesso e a facilidade do armazenamento.

Além da difusão, haveria uma nova relação com a informação contida na fonte digital, especialmente nos documentos textuais. nteDe modo semelhante ao que ocorreu com os livros digitais e com o advento do hipertexto, o documento histórico textual também se converte, como dissemos, em uma base de dados de strings. A possibilidade de buscas, intradocumento e interdocumentos, por meio de massivos acervos de dados e metadados digitais, apresenta diferenças na maneira de condução da pesquisa. A possibilidade de localizarmos - e, de certo modo, quantificarmos - a ocorrência de determinados termos em um vasto material textual permite acelerar o foco da atenção do historiador em relação a temas e assuntos de seu interesse de pesquisa.

Entretanto, a vantagem de tratar o "documento como string" pode tornar-se uma fonte de erros na pesquisa. 0 encontro de um termo de interesse pode vir a fragmentar a relação com o documento histórico, pois a busca automática subtrai a compreensão acerca do contexto de aparição da própria palavra. De modo semelhante ao que ocorreu com os livros digitais, podemos perder a noção do todo, ou, como sublinha Roger Chartier (2002: 23), "num certo sentido, no mundo digital todas as entidades textuais são como bancos de dados que procuram fragmentos cuja leitura absolutamente não supõe a compreensão ou percepção das obras em sua identidade singular".

Além disso, a lógica da pesquisa parece inverter-se, pois já deveríamos saber, em certo sentido, aquilo que desejaríamos encontrar. Ou seja, a própria escolha do termo de interesse ou das "palavras-chave" implica a existência de um conhecimento ou interpretação prévia daquilo que é possível de ser encontrado no(s) documento(s). Se considerarmos que tal busca seria apenas um momento inicial, para filtrarmos o que deve ou não ser analisado por uma 
leitura atenta, os problemas ainda assim persistem em no mínimo três aspectos. 0 primeiro é que a digitalização sempre pode comportar erros nos caracteres de documentos que não são nativamente digitais. Segundo, a linguagem tem a incrível capacidade de nos permitir falar das coisas sem que necessariamente mencionemos o nome delas. Por fim, e não menos grave, o horizonte de possibilidades daquilo que sabemos que vamos encontrar sempre pode ser surpreendido por algo que sequer imaginávamos que poderia ser encontrado.

A leitura diante da tela é geralmente descontínua, e busca, a partir de palavras-chave ou rubricas temáticas, o fragmento textual do qual quer apoderar-se (um artigo em um periódico, um capítulo em um livro, uma informação em um web site), sem que necessariamente sejam percebidas a identidade e a coerência da totalidade textual que contém esse elemento. (Chartier, 2002: 23)

Entretanto, para além dessas limitações, que retornaremos a discutir adiante, as novas modalidades de produção e transmissão dos textos e das fontes, que Chartier chama revolução, também são "uma mutação epistemológica fundamental" (Chartier, 2002: 108). As novas possibilidades abertas pela digitalização das fontes, sua disponibilização online, o desenvolvimento de ferramentas de busca textual e aplicativos de análise computadorizada têm impacto ainda não conclusivo e estimulante no trabalho hermenêutico do historiador.

Nos próximos tópicos, buscamos indicar caminhos possíveis de análise e reflexão sobre esses impactos no trabalho do historiador por meio do uso da HDB-BN.

\section{O CASO DA HEMEROTECA DIGITAL DA BIBLIOTECA NACIONAL}

$\Psi$ istoriadores das mais variadas filiações teóricas e de diferentes gerações vêm utilizando Brasileira da Biblioteca Nacional (HDB-BN), ${ }^{4}$ sobretudo a busca por palavra, nominativa. Entretanto, o uso da HDB não é acompanhado de uma necessária discussão teórico-metodológica acerca de seus impactos, transformações, possibilidades e limites no fazer do historiador. Na verdade, poderíamos afirmar que há, até certo ponto, uma negligência - quando não uma omissão intencional —, passando a falsa noção de que o pesquisador chegou aos resultados finais de sua pesquisa utilizando o tradicional método de leitura corrente.

Essa percepção fortalece-se quando realizamos uma análise em um banco de dados de revistas do repositório Scielo com classificação A1 na área de história pelo sistema de avaliação de periódicos Qualis Capes. De 1997 a 2017, em mais de 2.300 artigos disponíveis, realizamos uma busca automatizada pelo termo "Hemeroteca Digital", utilizando o software 
de análise qualitativa ATLAS.ti. ${ }^{5}$ Surpreendentemente, não foi encontrada nem sequer uma referência à Hemeroteca Digital. Essa ausência constitui um indício importante para nossa reflexão: mesmo se computarmos apenas os artigos publicados a partir da disponibilização da HDB para o público, no ano 2008, não encontramos nenhuma referência nos artigos publicados nas mais importantes revistas de história do Brasil.

Buscamos, neste tópico, elencar alguns problemas, estratégias e caminhos metodológicos de uma prática historiográfica digitalizada, colocando em destaque as novas possibilidades de resultados de pesquisa oriundos da utilização da HDB.

Essa ferramenta digital tem ampliado de maneira exponencial a possibilidade de fazermos novas perguntas e responder a elas com o auxílio dessa tecnologia. Sem a busca nominativa por palavras-chave disponibilizada pela HDB, os pesquisadores alcançariam os mesmos resultados por métodos analógicos? Essa questão é fundamental para uma reflexão sobre os impactos dessa ferramenta específica em nossa imaginação histórica.

Nos anos 1940, a BN iniciou o processo de microfilmagem dos periódicos, mas apenas em 1978 foi criado o Plano Nacional de Microfilmagem. ${ }^{6}$ Durante décadas, pesquisadores dedicaram horas a fio, girando e rebobinando os microfilmes, lendo minuciosamente cada página, cada coluna, cada sessão dos periódicos. Anotavam à mão o que interessava. Depois, os computadores portáteis facilitaram o trabalho da transposição da fonte do suporte do microfilme para o suporte digital. Os pesquisadores passaram a ter a oportunidade de transcrever imediatamente para um editor de texto o que interessava. Para preservação do original, acesso, mobilidade e velocidade da pesquisa, a mudança do suporte, do papel para o microfilme, foi uma transformação significativa no fazer historiográfico.

Entretanto, a partir de 2006, a mudança de suporte, associada à tecnologia digital, implicaria transformações na imaginação histórica em uma ordem sem precedentes. Nesse ano, a BN iniciou o trabalho de digitalização de parte de seu acevo. 0 projeto, que englobaria livros, partituras, fotos, revistas e periódicos, daria origem à BN Digital. Segundo o site da instituição, os objetivos da digitalização seriam a difusão das coleções, "diversificando sua esfera social e enriquecendo as possibilidades de acesso e uso", e a salvaguarda do acervo original.

0 acervo total da BN é de uma magnitude impressionante, e a seleção para a digitalização precisou considerar diversos fatores, como o valor e a importância históricos, a raridade, "assim como a relevância de coleções", a demanda dos usuários, itens de efemérides, fragilizados etc. Atualmente, a BN Digital conta com 2.078.154 — dois milhões e setenta e oito mil, cento e cinquenta e quatro - documentos digitalizados para livre acesso, sem contar os periódicos. $^{7}$ 
Como parte da BN Digital, temos acesso à Hemeroteca Digital Brasileira (HDB), um repositório de jornais, revistas, almanaques, anuários, boletins com acesso livre de qualquer equipamento conectado à internet. Nela, encontramos desde as primeiras publicações da imprensa brasileira no início do século XIX até os jornais impressos extintos do século XX. Além de ser livre e gratuita, com acesso de qualquer lugar do mundo, o diferencial da HDB é sua ferramenta de busca, avançada e bastante eficaz. Ao acessarmos o site <http://bndigital. bn.gov.br/hemeroteca-digital/>, encontramos a seguinte tela (Figura 1):

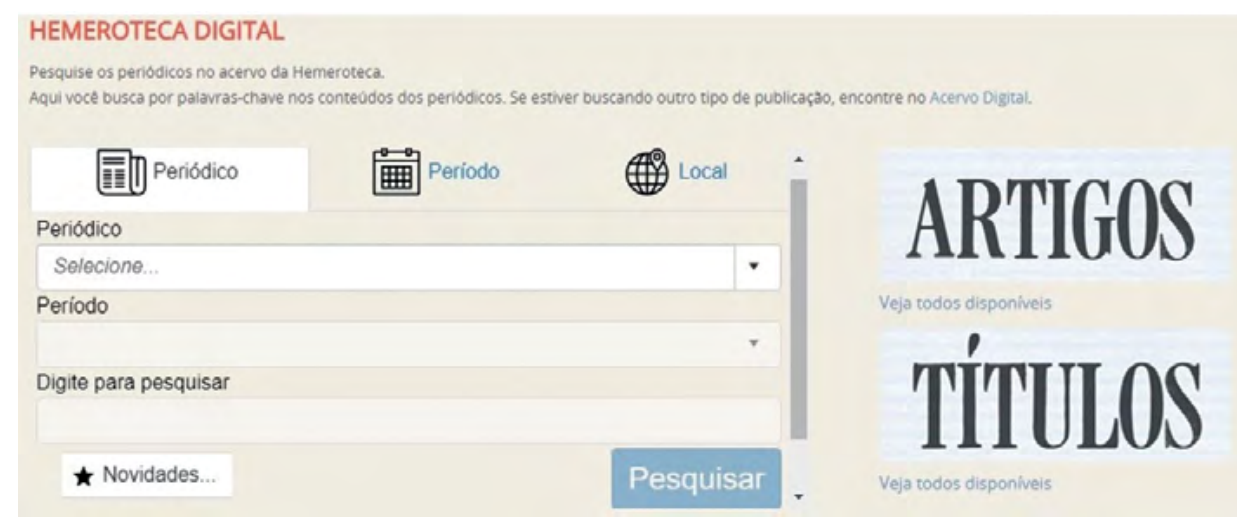

Figura 1 - Print screen da página de busca da HDB. Disponivel em: <bndigital.bn.gov.br/hemeroteca-digital/>. Acesso em: 25 jul. 2019.

As três abas de pesquisa são Periódico, Período e Local. Cada uma delas apresenta especificidades, servindo para objetivos distintos de cada pesquisador. Na aba Periódico, a busca está centrada em determinado periódico, o que possibilita analisar como um jornal aborda determinado assunto em um período específico: como a Gazeta de Notícias abordou a Lei do Ventre Livre e a Lei Áurea, por exemplo. Essa aba também é fundamental para aqueles que têm o próprio periódico como objeto de estudo: uma pesquisa sobre o Jornal do Commercio durante o Segundo Reinado, por exemplo.

A segunda aba, Período, é mais indicada para pesquisas sobre temas com marcos cronológicos ou recortes de tempo muito delimitados, em que o pesquisador deseje encontrar as representações e análises em um período específico. Nessa opção, ele pode selecionar um recorte temporal, adicionar um recorte geográfico ou optar por todas as regiões que o período contempla no acervo. 0 mesmo serve para o periódico. Por exemplo, você pode selecionar o período de 1880-1889, o local CE e buscar nos 57 periódicos disponíveis o termo desejado.

Por fim, a terceira aba: Local. Essa é a opção que mais abre possibilidades de busca para quem estuda trajetórias de indivíduos, as ações de grupos e associações, quem busca nomes, 
títulos, temas e assuntos em local e período delimitados. Com essa ferramenta de busca, podemos, por exemplo, colocar o nome de um sujeito que apareceu em uma fonte policial e delimitar a região, o período e o periódico.

Buscando esmiuçar uma possibilidade de método de pesquisa, vamos utilizar o exemplo de um personagem histórico, cuja trajetória, redes sociais e estratégias de ação política só se tornaram passíveis de reconstrução histórica a partir das possibilidades abertas pela HDB. Buscaremos na aba Local o nome de Moyses Zacharias da Silva.

Durante pesquisa anterior de um dos autores do artigo, o método utilizado para construir trajetórias, redes sociais e formas de mobilização política de sujeitos negros durante o pós-Abolição no Rio de Janeiro foi o seguinte: leitura e transcrição dos pedidos de licença enviados pelas associações carnavalescas para o chefe de polícia; em seguida, foi criado um banco de dados com as informações desses pedidos de licença (títulos das associações, endereços das sedes, nomes, profissões e endereços dos membros e das diretorias, tipos de pedidos, despachos etc.); depois, os nomes de associações e sujeitos foram utilizados na busca textual na HDB. Esse método foi complementado pela leitura corrente dos principais jornais e revistas que abordavam o carnaval nas duas primeiras décadas do século XX e pela busca em outras bases de dados (principalmente os Diários Oficiais da União, disponíveis para pesquisa online no site JusBrasiß por meio de busca nominal de indivíduos já encontrados tanto nas fontes policiais do Arquivo Nacional quanto nos periódicos da Biblioteca Nacional) (Brasil, 2016).

Essa metodologia tornou possível o acompanhamento de reconstrução das experiências, escolhas e redes de inúmeros indivíduos negros durante a Primeira República no Rio de Janeiro. A ferramenta de busca textual da HDB e o novo suporte das fontes possibilitaram elaborar novas perguntas, novos objetivos, encontrar novas respostas, que seriam impensáveis de outro modo. Para o estudo das trajetórias, o peso das novas tecnologias é muito promissor. Segundo Laura Putnam:

A relevância da digitalização em massa para esses objetivos analíticos deveria ser óbvia. Fontes de texto pesquisável possibilitam rastrear pessoas individuais (ou músicas, panfletos ou frases), permitindo-nos observar no nível micro os processos que geram, no agregado, fluxos e conexões de nível macro. À medida que os repositórios digitalizam e carregam fontes cada vez mais cotidianas, as possibilidades de usar a pesquisa de termos on-line para o que os historiadores costumavam chamar de vinculação de registro nominal expandem-se e expandem-se. (Putnam, 2016: 386)

Por meio da busca digital, encontramos Moyses Zacharias da Silva como presidente de clubes carnavalescos, participando de greves, de sindicatos, de comissões, da inauguração de 
escolas noturnas, como membro da Guarda Nacional, como eleitor e mesário e discursando para o presidente Hermes da Fonseca, com quem posou ao lado para uma fotografia em 1911 (Brasil, 2018). Assim, a ferramenta digital possibilitou uma reflexão profunda sobre as experiências de sujeitos negros na cidade do Rio de Janeiro, demonstrando suas complexas leituras políticas do presente e seus projetos de cidadania. Não seria possível atingir tais resultados pela leitura de cada uma das milhares de edições dos 17 periódicos divididos em 27 pastas de períodos cronológicos em que encontramos registros sobre tal personagem, ao longo das décadas de 1900, 1910, 1920 e 1930. No interior dessas pastas, o número total de páginas digitalizadas pesquisadas com esses parâmetros de busca atinge a marca impressionante de um 1.028.620 (milhão, vinte e oito mil, seiscentas e vinte) páginas. Entretanto, a busca completa foi realizada no conjunto total de páginas no acervo, que atualmente tem mais de 11 milhões de páginas digitalizadas. 0 uso da tecnologia digital alterou, portanto, profundamente a hermenêutica e a epistemologia da história, possibilitando novos resultados de pesquisa.

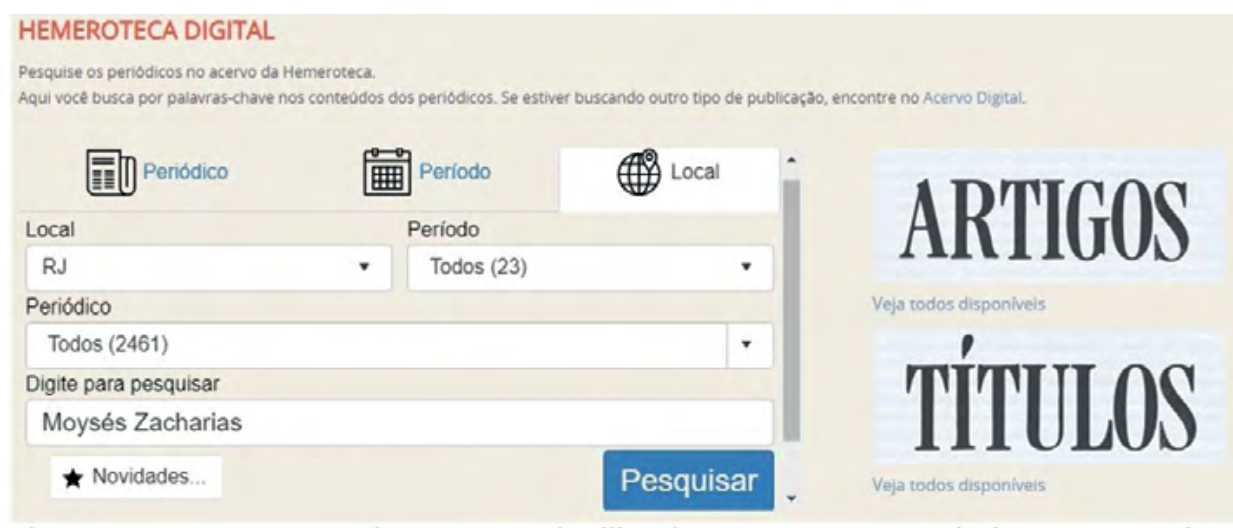

Figura 2 - Print screen com a busca por Local, utilizando o termo "Moyses Zacharias" para o Local RJ, todos os períodos e todos os periódicos.

E, por isso mesmo, é importante entender o funcionamento da HDB. Após clicar em "pesquisar", uma nova página abre-se com os resultados gerais da busca. A ferramenta de busca digital apresentará todas as ocorrências encontradas em uma listagem, contendo as seguintes informações: o título do periódico, as páginas totais digitalizadas, o número de ocorrências e as opções de "ir para a primeira página" do periódico e "ir para a primeira ocorrência" (Figura 3). 


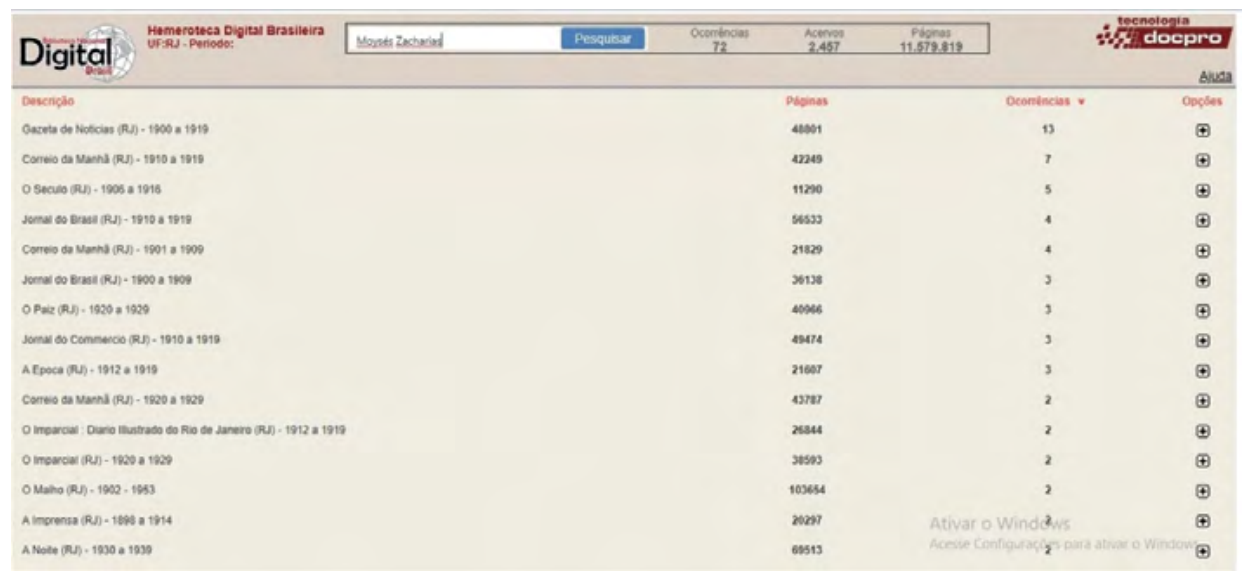

Figura 3 - Print screen da página de resultados da busca realizada.

Após selecionar o periódico desejado, uma nova página se abrirá. Por exemplo, clicamos em "A União (RJ) - 1905 a 1950". Como podemos ver na imagem da Figura 4, podemos navegar de três modos em cada periódico selecionado: 1) navegar por ocorrências — a ferramenta passará para a próxima página em que o termo procurado foi encontrado, que estará sempre destacado em verde no corpo do texto; 2) navegar por páginas da edição — assim, é possível ler toda a edição de cada ocorrência; c) abrir todo o acervo daquele periódico e navegar por todas as edições livremente.

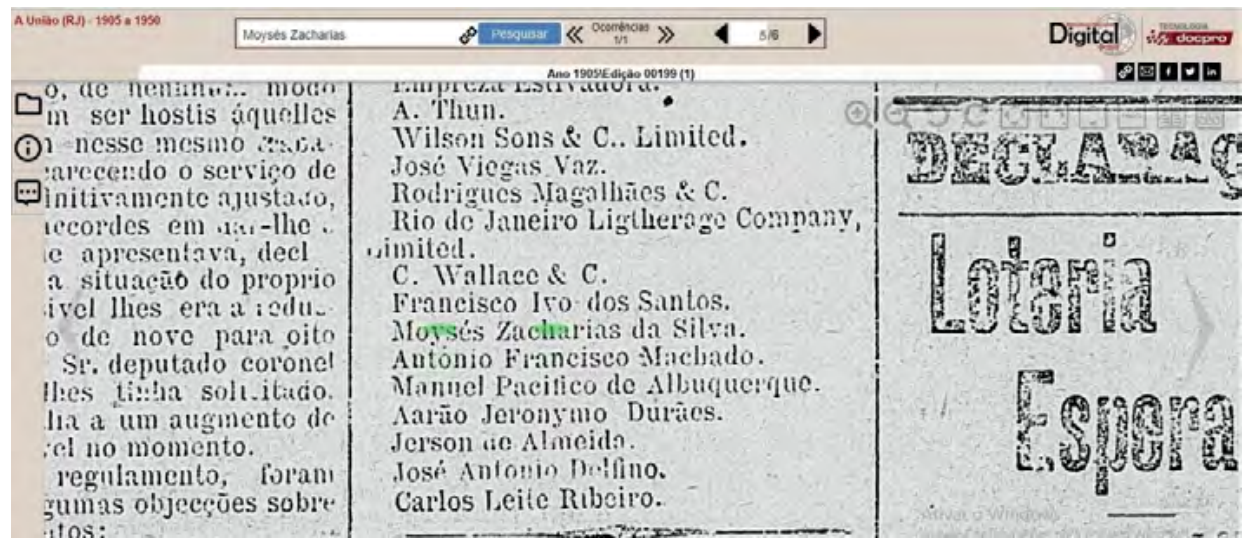

Figura 4 - Print screen da página com a busca. 0 termo pesquisado é destacado em verde ( $A$ União, edição 199, de 19 de julho de 1905, p. 5. Disponível em: <http://memoria.bn.br/DocReader/799670/844>. Acesso em: 26 jun. 2019). 
A soma dessas três possibilidades de navegação e leitura disponibilizadas pela HDB cria condições de superação da principal crítica feita a seu uso: de que a busca nominativa levaria a uma quase inevitável leitura e análise fragmentada, sem a compreensão do todo que forma esse tipo de fonte.

Muitos jornais permitem que o leitor salve a página como imagem (.jpeg) em seu computador. Outros podem ser acessados (com busca e leitura), mas sem a opção de salvar — como o Jornal do Brasil e o Jornal do Commercio. Outras ferramentas importantes disponíveis são o zoom in e out; salvar o hiperlink da página atual, o que possibilita formas mais eficazes de catalogação e acesso posterior; acessar as informações detalhadas sobre o acervo do periódico específico (Figura 5) e acessar todas as pastas dos anos do acervo (Figura 6). 0 hiperlink, as informações detalhadas e o acesso às pastas com todas as edições digitalizadas permitem-nos demonstrar os caminhos metodológicos realizados durante a pesquisa.

\begin{tabular}{|c|c|}
\hline (i) Informações do acervo & $x$ \\
\hline $\begin{array}{l}\text { Cód.: TRB00448.0072 } \\
\text { Rótulo: } 799670 \\
\text { Nome: A União (RJ) - } 1905 \text { a } 1950\end{array}$ & \\
\hline PASTA & PAGINAS \\
\hline Ano 1905 & $0-$ \\
\hline -Edição 00001 & 6 \\
\hline -Edição 00002 & 4 \\
\hline -Edição 00003 & 4 \\
\hline -Edição 00004 & 4 \\
\hline -Edição 00005 & 4 \\
\hline -Edição 00006 & 4 \\
\hline -Edição 00007 & 4 \\
\hline -Edição 00008 & 4 \\
\hline -Edição 00009 & 4 \\
\hline -Edição 00010 & 4 \\
\hline -Edição 00011 & 4 \\
\hline -Edicão 00012 & $4=$ \\
\hline Total de pastas: 1.615 & Total de páginas: 8.563 \\
\hline DocReader Web - Ver. $4.4 \cdot 0.0$ - 64 bits & Copyright 1987-2018 \\
\hline
\end{tabular}

Figura 5 - Print screen das "Informações do acervo" referentes ao periódico "A União (RJ)".

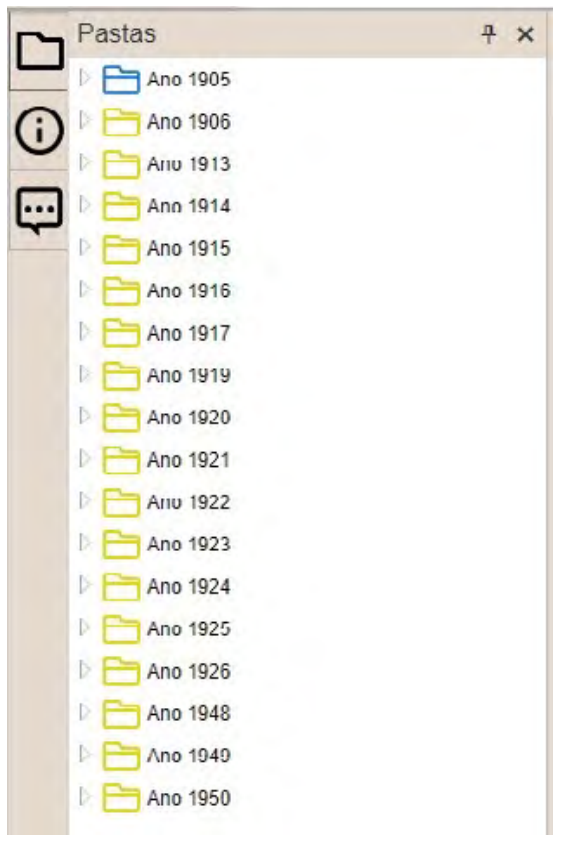

Figura 6 - Print screen da lista das "Pastas" referentes ao periódico "A União (RJ)". 
É importante destacar que as ocorrências a que temos acesso não correspondem à totalidade das vezes que o termo aparece no periódico, mas, sim, às vezes que a ferramenta de busca foi capaz de encontrar o tal termo pelo Reconhecimento Ótico de Caracteres (Optical Character Recognition - OCR). Na edição de 19 de julho de 1905 do jornal A União, a ferramenta encontrou o nome de Moyses Zacharias da Silva assinando como um dos representantes dos operários uma carta sobre uma greve dos operários estivadores. Entretanto, não foi capaz de encontrar o mesmo nome na mesma página no corpo da carta que Moyses assinou (Figura 7).

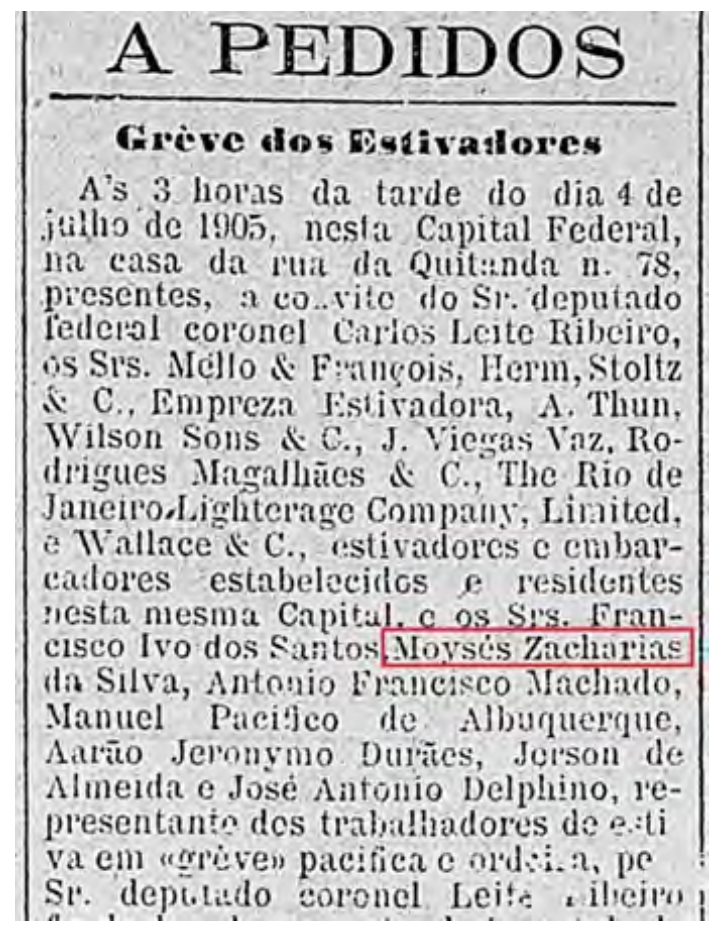

Figura 7 - Recorte da p. 5 da edição 199, de 19 de julho de 1905, do jornal A União. 0 nome de Moyses Zacharias não foi encontrado e marcado em verde pela busca da HDB. Disponível em: <http://memoria.bn.br/ DocReader/799670/844>. Acesso em: 26 jun. 2019.

Outro exemplo das limitações do OCR pode ser encontrado na edição 305 da Revista da Semana. Nela, encontramos uma página contendo cinco fotografias de presidentes de associações carnavalescas do Rio de Janeiro no ano 1906. Entre eles encontramos nosso personagem. No entanto, a ferramenta de busca não reconheceu "Moyses Zacharias da Silva" como uma ocorrência. Sua foto, fundamental para a pesquisa que um dos autores do artigo vinha desenvolvendo, não seria encontrada apenas pela busca nominativa (Figura 8). 


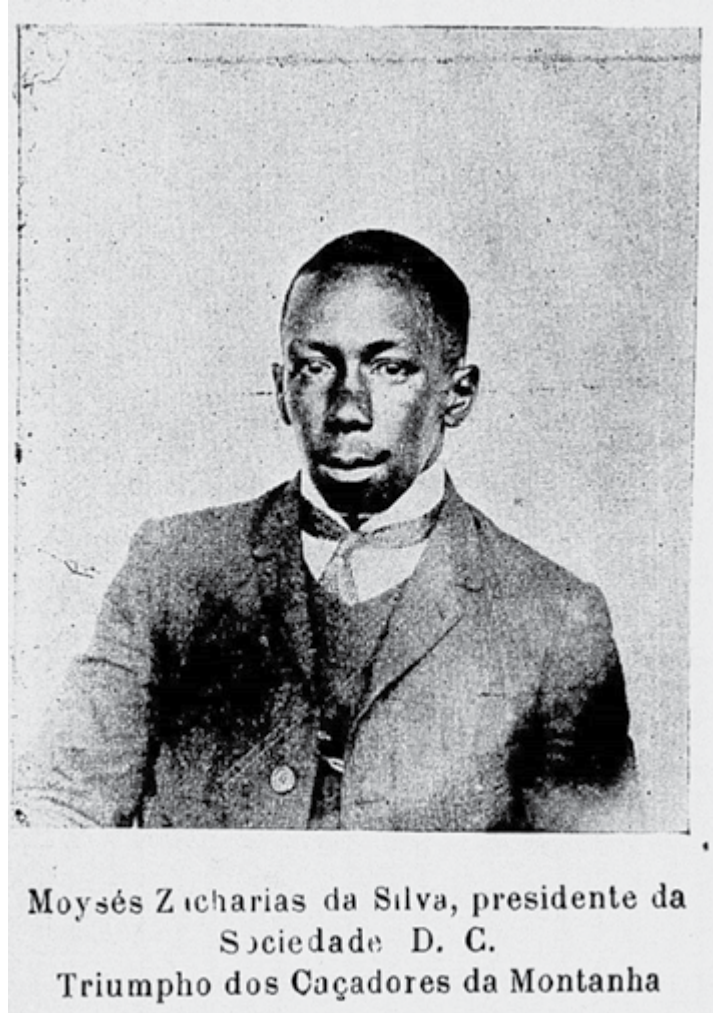

Figura 8 - Detalhe da p. 20 da edição 305, de 18 de março de 1906, da Revista da Semana. Disponível em: <http:/l memoria.bn.br/DocReader/025909_01/4313>. Acesso em: 26 jun. 2019.

Isso quer dizer que devemos deixar de usar a busca textual? Segundo Tim Hitchcock (2013: 14), a busca por palavras é, ao mesmo tempo, libertadora e perigosa, pois também resultou em um substancial desenraizamento do conhecimento. Para Laura Putnam (2016: 377), tais tecnologias explodiram o alcance e a velocidade das descobertas, porém nossa habilidade "para ler com precisão as fontes que encontramos e avaliar seus significados não pode ser magicamente acelerada", e com isso corremos o risco de criar um retrato parcial do passado do mundo inteiro.

Essas limitações apontadas por Hitchcock e Putnam não devem inibir-nos ao uso da busca textual na HDB. Devem servir como um alerta constante para qualquer pesquisador que se debruce sobre a al.história digital. Porém, gostaríamos de argumentar que, no próprio escopo da HDB, encontramos os subsídios para escapar dos problemas apontados: a leitura fragmentada, que perde os significados contextuais, e o conhecimento parcial da fonte e seu conteúdo. Por meio da HDB, podemos, além da busca nominativa, buscar e navegar pelos 
acervos completos dos periódicos. Podemos, portanto, realizar as leituras diárias, como era feito nas máquinas de microfilme décadas atrás. Podemos (e devemos) também registrar as informações detalhadas sobre cada periódico estudado, o acervo, o volume de digitalizações, o período de publicações, seus donos, redatores, editores, jornalistas, suas imagens, gravuras, colunas, preço, circulação, etc., inclusive confrontando com demais fontes e com a bibliografia. Portanto, os problemas metodológicos são responsabilidade do historiador, que muitas vezes, por descuido ou desconhecimento técnico, usa a tecnologia como mera forma de confirmar seus desejos e hipóteses.

Uma crítica mais importante, em nossa concepção, recai sobre a escrita da história. Historiadores que utilizam a HDB, e qualquer outro método digital, não têm dedicado a devida atenção e espaço na escrita às reflexões metodológicas de seu uso. Acreditamos que é fundamental explicitar o método, as ferramentas tecnológicas utilizadas durante a pesquisa e sua experiência no processo, para corroborar sua contextualização e interpretação final das fontes. Gibbs e Owens (2013: 159) afirmam que

[...] novos métodos usados para explorar e interpretar dados históricos exigem um novo nível de transparência metodológica na escrita histórica. Exemplos incluem discussões de consultas de dados, fluxos de trabalho com ferramentas específicas e a produção e interpretação de visualizações de dados. No mínimo, as publicações de pesquisa dos historiadores precisam refletir novas prioridades que explicam o processo de interfacear, explorar e, em seguida, compreender as fontes históricas de uma forma fundamentalmente digital — ou seja, a hermenêutica dos dados.

Essas críticas são fundamentais e apontam para os limites do uso da HDB, mas também da história digital como um todo. Entretanto, apesar de sua pertinência, elas não devem ser entendidas como uma barreira intransponível para o uso de ferramentas, fontes e métodos digitais. Pelo contrário, devem servir como impulso para a reflexão mais aprofundada sobre seus aspectos teórico-metodológicos. Para tanto, propomos um breve mergulho nas possibilidades oferecidas pelos CAQDAS, por meio da análise da utilização do aplicativo ATLAS.ti na pesquisa, tratamento, análise e escrita da história e na superação das limitações apontadas.

\section{CAQDAS: O ATLAS.TI E NOVOS CAMINHOS METODOLÓGICOS PARA A HISTÓRIA}

pesquisa nas ciências humanas vem, desde a década de 1990, passando por alterações
relacionadas com o uso das tecnologias (Rioufreyt, 2019; Lage, 2011; Wynn, 2009). Nos últimos anos, parte significativa dessas alterações está associada ao uso de uma classe de 
aplicativos agrupados sob o nome de CAQDAS, acrônimo de língua inglesa para computer assisted qualitative data analysis, ou análise de dados qualitativos assistida por computador. Uma vez que o material que será analisado tenha sua origem em dispositivos digitais ou tenha sido convertido para o formato digital, é possível efetuarmos, dentro do ambiente digital desses programas, a totalidade das etapas da pesquisa qualitativa. Existem aplicativos com diversas funcionalidades e que são capazes de tratar dados nos mais variados formatos, seja em áudio, texto, vídeo ou imagem.

O ATLAS.ti ${ }^{9}$ - ao lado do NVivo ${ }^{10}$ e do MAXQDA ${ }^{11}$ — é um dos CAQDAS comerciais de código fechado ${ }^{12}$ mais antigos disponível no mercado. Comum a todos esses aplicativos está a possibilidade de analisarmos livros, artigos, entrevistas, músicas, filmes, quadros, fotos, websites, em suma, praticamente todo e qualquer material de pesquisa e/ou trabalho nos mais diversos campos ou áreas. Resumidamente, uma vez inseridos documentos digitais no aplicativo, temos de criar rótulos ou códigos. Em seguida, à medida que vamos analisando o material - lendo os textos, ouvindo os áudios, assistindo aos vídeos, vendo as imagens etc. - - devemos ir selecionando os trechos dos documentos relacionados com os rótulos ou códigos (codes) que foram criados. Como resultado, teremos um conjunto de trechos do documento (denominados quotations) grifados ou sublinhados segundo as categorias que foram criadas. Uma metáfora bastante útil é imaginarmos um livro cheio de grifos e anotações nos cantos das páginas — ou em post-its coloridos — , só que no formato digital. ${ }^{13}$

As quotations, nas palavras de Konopásek (2007: 283), são as unidades elementares de análise, não apenas porque seus sentidos estão razoavelmente contidos e, portanto, acessíveis para nossas mentes e processo mental, mas porque elas também são de um tamanho físico razoável para serem selecionadas e processadas de um modo material — por olhos, mãos, listas, boxes, telas de computador. As quotations, por sua vez, estão conectadas aos códigos (codes), ou representam "as categorizações destes trechos através de processos interpretativos" (Alves e Nascimento, 2018: 243). Ou, em uma definição mais abrangente: "uma palavra ou frase curta que atribui simbolicamente um atributo que resume, salienta, captura a essência e/ou evoca uma porção de dados visuais ou baseados na linguagem" (Saldana, 2015: 3).

Uma vez que o(s) material(is) tenha(m) sido lido(s) e codificado(s), ele é capaz de gerar relatórios com o conteúdo dos documentos (com as quotations), além de redes (networks) que são representações gráficas - da estrutura dos códigos (codes), juntamente com os trechos grifados correspondentes. É possível ainda criar grupos de documentos (por exemplo, todas as revistas de determinado ano, todas as imagens de um pintor, todos os áudios de um entrevistado) e grupos de códigos (por exemplo, códigos para análise de elementos das imagens de jornais 
carnavalescos do século XIX). Essas duas funcionalidades básicas permitiriam ao historiador ter uma visualização e uma organização dos documentos de modo inteiramente digital.

No caso específico de documentos textuais, há ainda outra funcionalidade: a possibilidade de busca e codificação automatizada de trechos, denominada autocoding. Em outras palavras, o programa permite fazer buscas por palavras-chave em todo o material em formato texto (.txt, .doc, .docx, .pdf etc.), desde que os documentos (especialmente os que estão em formato .pdf) tenham passado por um reconhecimento óptico de caracteres, ou OCR. Uma vez realizada essa codificação automatizada, é possível, da mesma maneira, produzir um documento com todos os trechos codificados. Além de "ler" os textos - ou, mais adequadamente, processar as strings - , o autocoding fornece uma visualização de todas as ocorrências do termo buscado dentro do contexto do documento.

As possibilidades de análise qualitativa abertas pelo uso do ATLAS.ti potencializam sobremaneira a pesquisa realizada na HDB. Com o exponencial aumento, com a abundância das fontes acessadas e arquivadas digitalmente (Fickers, 2012), o pesquisador encara a urgência de maior velocidade, maior organização e maior capacidade de recuperar as informações (Nascimento, 2016: 229). Por exemplo, ao buscarmos nos 204 periódicos cariocas, entre 1910 e 1919, disponíveis na HDB o termo "Flor do Abacate" - título de uma famigerada associação carnavalesca carioca na primeira metade do século XX — encontramos 1.272 ocorrências. Ainda que todas elas sejam armazenadas e minimamente catalogadas pelo pesquisador — por mais que tenham significados em si, pela maneira fragmentada como foram selecionadas e arquivadas e, sobretudo, por conta de seu volume - , pode ser que o enorme potencial gerado pela prática de pesquisa na HDB seja perdido. 0 historiador pode "ser afundado em informações" (Konopásek, 2007: 283).

A codificação das fontes digitais pelo ATLAS.ti permite-nos criar relevância e significação em um manancial de informações. Isso é fundamental para as pesquisas que têm utilizado a HDB, pois o volume e a fragmentação dos dados obtidos tornam a análise tradicional, analógica, limitada e arriscada. É cada vez mais difícil fazer visível o corpo documental. Consequentemente, a análise e a escrita da história tendem a esbarrar em uma interpretação parcial e fragmentada. Esse problema metodológico afeta diretamente as operações mais básicas da historiografia: selecionar a fonte, criticá-la — interna e externamente - e interpretá-la. Como afirma Konopásek (2007: 293), pelo ATLAS.ti podemos agir transversalmente, por exemplo, construindo conexões entre jornais, leis, artigos científicos, imagens, formando um "texto multivocal", que expressa fisicamente nosso movimento progressivo do contexto e sentidos originais para o argumento histórico. 


\section{CONSIDERAÇÕES FINAIS}

0 historiadores têm utilizado tantas ferramentas digitais em tão variadas etapas do pro cesso de pesquisa, análise, escrita, assim como na elaboração de cursos, aulas, palestras, workshops, que talvez a pergunta correta a fazer seja qual história hoje não é digital. Por isso mesmo, acreditamos na necessidade de um "upgrade" teórico-metodológico entre os historiadores, tanto na pesquisa quanto na formação de novos pesquisadores e professores de história, que enfrentarão as salas de aula repletas de estudantes imersos no "mundo virtual".

Ao longo do artigo, buscamos apresentar as limitações do uso do sistema de busca da HDB inseridas em reflexões teórico-metodológicas que nos possibilitem utilizar o melhor dessa ferramenta, atingindo todas as suas potencialidades na transformação epistemológica do trabalho do historiador. A busca textual em milhões de páginas de periódicos cria o risco da leitura superficial, parcial, fragmentada. Entretanto, qualquer pesquisa sem rigor metodológico, mesmo que debruçada diante de um jornal em papel, sempre terá esse mesmo risco.

Desse modo, a ferramenta de busca da HDB oferece-nos os caminhos para superar tais limitações, visto que podemos não apenas buscar palavras, mas também acessar todo o acervo digitalizado, lê-lo página por página, dia a dia, ano a ano, assim como podemos acessar os metadados e analisar o escopo do acervo disponível. É possível, portanto, realizar a crítica heurística da fonte digitalizada, tanto quanto da fonte no suporte material anterior. Mas agora com novas características, elementos, possibilidades e limitações.

Para ampliar essas possibilidades analíticas, propomos aqui a utilização crítica de ferramentas CAQDAS, em nosso caso o ATLAS.ti, como ferramenta de suporte ao trabalho do historiador, especialmente no cenário da abundância das fontes digitais. Por meio do aplicativo, podemos minimizar os riscos de uma leitura e interpretação fragmentada e superficial. É possível recuperar e conectar os dados com velocidade, organização e rigor científico, ao mesmo tempo que podemos tornar visíveis os argumentos, redes, estruturas conceituais e analíticas. 0 conjunto volumoso de fontes digitais que poderia nos soterrar passa a ser controlável e acessível na tela do computador.

Por fim, é importante encerrar o artigo com a afirmação de que nenhuma dessas ferramentas substitui o trabalho minucioso, dedicado e paciente do historiador. Nem a HDB, nem o ATLAS.ti substituem a leitura da fonte, a elaboração das perguntas e dos problemas, a construção conceitual analítica e a erudição e o conhecimento de contextos e bibliografia. As ferramentas potencializam nossas habilidades analíticas, possibilitam que novas perguntas sejam formuladas, e novas respostas, atingidas. Mas com muito trabalho e rigor diante do computador. 


\section{NOTAS}

1 Essa e as demais traduções presentes no artigo foram feitas pelos autores.

2 Cf. Almeida (2011), Bello e Vasconcelos (2017), Câmara e Benício (2017), Cavalcanti (2017), Henriques (2017), Lucchesi (2014), Silva (2017), Soares (2017), Soares et al. (2017), Villa (2015), Worcman e Henriques (2017).

3 Não podemos desdobrar os detalhes técnicos do OCR, que é um acrônimo para o inglês Optical Character Recognition. Obviamente, podem ocorrer erros na "busca automatizada" de palavras-chave que dependem da qualidade do reconhecimento do texto. Atualmente, os algoritmos de OCR, como o Tesseract (cf. <https:// github.com/tesseract-ocr>. Acesso em: 27 jul. 2019) têm espantosa capacidade de acerto. Com o tempo, muito provavelmente a tendência é que o grau de acerto aumente ainda mais.

4 Disponível em: <http://bndigital.bn.gov.br/hemeroteca-digital/>. Acesso em: 27 jul. 2019.

5 "[...] a principal e mais fundamental característica do ATLAS.ti é a possibilidade de codificarmos livros, artigos, entrevistas, músicas, filmes, quadros, fotos, websites, em suma, praticamente todo e qualquer material de pesquisa e/ou trabalho nos mais diversos campos ou áreas. Tudo aquilo que fazíamos através de lápis, canetas coloridas e papel — anotações de leituras, grifos, fichamentos, comentários, insights, etc. [...] agora pode ser realizado dentro deste software" (Alves e Nascimento, 2018: 243). Para mais informações, cf. Friese (2014).

6 Informaç̧ões retiradas do site da BN Digital. Disponível em: <http://bndigital.bn.gov.br/sobre-a-bndigital/>. Acesso em: 27 jul. 2019.

7 Disponível em: <http://bndigital.bn.gov.br/>. Acesso em: 23 jul. 2019.

8 Disponível em: <http://www.jusbrasil.com.br>. Acesso em: 24 jun. 2019.

9 Disponível em: <https://atlasti.com/>. Acesso em: 22 jun. 2019.

10 "NVivo é um software que suporta métodos qualitativos e variados de pesquisa. Ele é projetado para ajudar você a organizar, analisar e encontrar informações em dados não estruturados ou qualitativos como: entrevistas, respostas abertas de pesquisa, artigos, mídia social e conteúdo web." Disponível em: <http:/l www.qsrinternational.com/nvivo-portuguese>. Acesso em: 22 jun. 2019.

11 "MAXQDA é um pacote de softwares líder mundial em pesquisa de métodos mistos e qualitativos. Ele analisa todos os tipos de dados - de textos a imagens e arquivos de áudio/vídeo, sites, tweets, discussões em grupos focais, respostas a pesquisas e muito mais." Disponível em: $<$ https://www.maxqda.com/>. Acesso em: 22 jun. 2019.

120 software proprietário de código fechado é um software para computadores licenciado com direitos exclusivos para o produtor e que não permite aos usuários alterar a estrutura algorítmica do código-fonte (a linguagem de programação de que é feito o aplicativo). Ou seja, ao usarmos tais aplicativos, ficamos impossibilitados de consertar os erros e/ou ficamos dependentes de "bugs", que precisam de novas versões corrigidas pelos proprietários.

13 Para uma descrição pormenorizada do aplicativo ATLAS.ti e de suas funções, cf. Alves e Nascimento (2018: 241-265). 


\section{REFERÊNCIAS BIBLIOGRÁFICAS}

ALMEIDA, F. C. de. 0 historiador e as fontes digitais: uma visão acerca da internet como fonte primária para pesquisas históricas. Aedos, v. 3, n. 8, 2011.

ALVES, P. C. B.; NASCIMENTO, L. F. Novas fronteiras metodológicas nas ciências sociais. Salvador: EDUFBA, 2018.

AYERS, E. L. The pasts and futures of digital history. History News, v. 56, n. 4, p. 5-9, 2001.

BACA, M. Introduction to metadata. Los Angeles: Getty Publications, 2008.

BELLO, R. S.; VASCONCELOS, J. A. O videogame como mídia de representação histórica. Revista Observatório, v. 3, n. 5, p. 216, 2017.

BERRY, D. M. Understanding digital humanities. Reino Unido: Palgrave Macmillan, 2012.

BOLICK, C. M. Digital archives: democratizing the doing of history. International Journal of Social Education, v. 21, n. 1, p. 122-134, 2006.

BRASIL, E. Carnavais atlânticos: cidadania e cultura negra no pós-Abolição do Rio de Janeiro, Brasil e Porto de Espanha, Trinidad (1838-1920). 2016. Tese (Doutorado), Universidade Federal Fluminense, Niterói, 2016.

. Moysés Zacharias: carnaval, cidadania e mobilizações negras no Rio de Janeiro (1900-1920). In: ABREU, M.; XAVIER, G.; MONTEIRO, L.; BRASIL, B. (Org.). Cultura negra: trajetórias e lutas de intelectuais negros. Niterói: Eduff, 2018.

CÂMARA, S.; BENÍCIO, M. História digital: entre as promessas e armadilhas da sociedade informacional. Revista Observatório, v. 3, n. 5, p. 38-56, 2017.

CAVALCANTI, M. T. Os websites dos centros de documentação e a pesquisa histórica: uso de fontes digitais. Revista Observatório, v. 3, n. 5, p. 169, 2017.

CHARTIER, R. Os desafios da escrita. São Paulo: Unesp, 2002.

CHAUDHURI, B. B. (Ed.). Digital document processing: major directions and recent advances. 1. ed. Londres: Springer-Verlag London, 2007.

COHEN, D. J. et al. Interchange: the promise of digital history. The Journal of American History, v. 95, n. 2, p. 452-491, 2008.

FICKERS, A. Towards a new digital historicism? Doing history in the age of abundance. Journal of European History and Culture, v. 1, n. 1, 2012.

FISH, A. et al. Birds of the internet. Journal of Cultural Economy, v. 4, n. 2, p. 157-187, 2011.

FRIESE, S. Qualitative data analysis with ATLAS.ti. 2. ed. Los Angeles: Sage, 2014.

GIBBS, F.; OWENS, T. The hermeneutics of data and historical writing. In: Writing history in the digital age. Ann Arbor, MI: University of Michigan Press, 2013. p. 159-170.

GIL, T. L.; BRESCIANO, J. A. (Ed.). La historiografía ante el giro digital: reflexiones teóricas y prácticas metodológicas. Montevidéu: Ediciones Cruz del Sur, 2015.

GOLD, M. K. Debates in the digital humanities. Minneapolis: University of Minnesota Press, 2012. 
HENRIQUES, R. M. N. Narrativas, patrimônio digital e preservação da memória no Facebook. Revista Observatório, v. 3, n. 5, p. 123, 2017.

HITCHCOCK, T. Confronting the digital: or how academic history writing lost the plot. Cultural and Social History, v. 10, n. 1, p. 9-23, 2013.

KONOPÁSEK, Z. Making thinking visible with ATLAS.ti: computer assisted qualitative analysis as textual practices. Historical Social Research/Historische Sozialforschung, Suplemento, n. 19, p. 276-298, 2007.

LAGE, M. Os softwares tipo CAQDAS e a sua contribuição para a pesquisa qualitativa em educação. ETD: Educação Temática Digital, v. 12, n. 2, p. 42-58, 2011.

LUCCHESI, A. Digital history e storiografia digitale: estudo comparado sobre a escrita da história no tempo presente (2001-2011). 2014. Dissertação (Mestrado), Universidade Federal do Rio de Janeiro, Rio de Janeiro, 2014.

MAYER-SCHÖNBERGER, V.; CUKIER, K. Big data: a revolution that will transform how we live, work, and think. Londres: John Murray Publishers, 2013.

NASCIMENTO, L. F. A sociologia digital: um desafio para o século XXI. Sociologias, v. 18, n. 41, p. 216-241, 2016.

PUTNAM, L. The transnational and the text-searchable: digitized sources and the shadows they cast. The American Historical Review, v. 121, n. 2, p. 377-402, 2016.

RIOUFREYT, T. Réanalyser des enquêtes qualitatives à I'aide de CAQDAS. Bulletin of Sociological Methodology/ Bulletin de Méthodologie Sociologique, v. 143, n. 1, p. 77-106, 2019.

SALDANA, J. The coding manual for qualitative researchers. Los Angeles: Sage, 2015.

SCHREIBMAN, S.; SIEMENS, R.; UNSWORTH, J. A companion to digital humanities. Nova York: John Wiley \& Sons, 2008.

SILVA, C. E. da. 0 uso do cinema no ensino de história em consonância com as novas demandas da história pública digital. Revista Observatório, v. 3, n. 5, p. 147, 2017.

SOARES, F. da S. Clio entre a digital history e a storiografia digitale: a oficina historiográfica de Anita Lucchesi e suas contribuições à história digital no Brasil. Revista Observatório, v. 3, n. 5, p. 669-715, 2017.

2017.

et al. História digital: perspectivas, experiências e tendências. Revista Observatório, v. 3, n. 5, p. 25 ,

VILLA, C. E. V. Georreferência de mapas históricos: os casos de Cartagena de Indias colonial e do Rio de Janeiro imperial. Locus: Revista de História, v. 21, n. 2, 2015.

VINCK, D. Humanités numériques: la culture face aux nouvelles technologies. Paris: Le Cavalier Bleu, 2016.

WORCMAN, K.; HENRIQUES, R. M. N. Curadoria colaborativa: uma experiência digital do Museu da Pessoa. Revista Observatório, v. 3, n. 5, p. 57, 2017.

WYNN, J. R. Digital sociology: emergent technologies in the field and the classroom. Sociological Forum, v. 24, n. 2, p. 448-456, 2009. 